\title{
Populations at risk for severe or complicated influenza illness: systematic review and meta-analysis
}

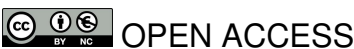

\author{
Dominik Mertz assistant professor ${ }^{12}$, Tae Hyong Kim researcher ${ }^{2}$, Jennie Johnstone researcher ${ }^{2}$, \\ Po-Po Lam researcher ${ }^{34}$, Michelle Science staff physician ${ }^{5}$, Stefan P Kuster staff physician ${ }^{6}$, Shaza \\ A Fadel researcher ${ }^{4}$, Dat Tran assistant professor ${ }^{5}$, Eduardo Fernandez researcher ${ }^{2}$, Neera \\ Bhatnagar librarian ${ }^{7}$, Mark Loeb professor ${ }^{289}$
}

\begin{abstract}
'Department of Medicine, McMaster University, Hamilton, ON, Canada; ${ }^{2}$ Department of Clinical Epidemiology and Biostatistics, McMaster University, Hamilton; ${ }^{3}$ Mount Sinai Hospital, Toronto, ON, Canada; ${ }^{4}$ Division of Epidemiology, Dalla Lana School of Public Health, University of Toronto, Toronto; ${ }^{5}$ Department of Pediatrics, The Hospital for Sick Children, University of Toronto, ON, Canada; ${ }^{6}$ University Hospital and University of Zurich, Zurich, Switzerland; ${ }^{7}$ Health Sciences Library, McMaster University, Hamilton; ${ }^{8}$ Department of Pathology and Molecular Medicine, McMaster University, Hamilton; ${ }^{9}$ Michael G DeGroote Institute for Infectious Disease Research, McMaster University, Hamilton
\end{abstract}

\begin{abstract}
Objective To evaluate risk factors for severe outcomes in patients with seasonal and pandemic influenza.

Design Systematic review.

Study selection Observational studies reporting on risk factor-outcome combinations of interest in participants with influenza. Outcomes included death, ventilator support, admission to hospital, admission to an intensive care unit, pneumonia, and composite outcomes.

Data sources Medline, Embase, CINAHL, Global Health, and the Cochrane Central Register of Controlled Trials to March 2011.

Risk of bias assessment Newcastle-Ottawa scale to assess the risk of bias. GRADE framework to evaluate the quality of evidence.

Results 63537 articles were identified of which 234 with a total of 610 782 participants met the inclusion criteria. The evidence supporting risk factors for severe outcomes of influenza ranged from being limited to absent. This was particularly relevant for the relative lack of data for non-2009 H1N1 pandemics and for seasonal influenza studies. Limitations in the published literature included lack of power and lack of adjustment for confounders was widespread: adjusted risk estimates were provided for only $5 \%$ of risk factor-outcome comparisons in 39 of $260(15 \%)$ studies. The level of evidence was low for "any risk factor" (odds ratio for mortality $2.77,95 \%$ confidence interval 1.90 to 4.05 for pandemic influenza and $2.04,1.74$ to 2.39 for seasonal influenza), obesity (2.74, 1.56 to 4.80 and $30.1,1.74$ to 2.39$)$, cardiovascular diseases (2.92, 1.76 to 4.86 and $1.97,1.06$ to 3.67 ), and neuromuscular disease $(2.68,1.91$ to 3.75 and $3.21,1.84$ to 5.58$)$. The level of evidence was
\end{abstract}

very low for all other risk factors. Some well accepted risk factors such as pregnancy and belonging to an ethnic minority group could not be identified as risk factors. In contrast, women who were less than four weeks post partum had a significantly increased risk of death from pandemic influenza $(4.43,1.24$ to 15.81$)$

Conclusion The level of evidence to support risk factors for influenza related complications is low and some well accepted risk factors, including pregnancy and ethnicity, could not be confirmed as risks. Rigorous and adequately powered studies are needed.

\section{Introduction}

Influenza is a major global cause of illness and death, resulting in an estimated three to five million cases of severe influenza illness and 250000 to 500000 deaths annually. ${ }^{1-3}$ The risk of complications from influenza, including lower respiratory tract infection, admission to hospital, and death vary depending on factors such as age and the type of comorbidity that may be present. ${ }^{12}$ Currently, the World Health Organization and most countries prioritise specific high risk groups for vaccination. ${ }^{2-6}$ Although some recommendations are consistent, such as vaccination of healthcare workers, pregnant women, and those with certain high risk conditions, there are also discrepancies, such as the age groups that need to be prioritised (table $1 \Downarrow$ ). Despite the widely accepted public health policy of recommending vaccination to groups believed to be at high risk for complications of influenza, a comprehensive and systematic review of the evidence defining these groups is lacking. 
Assessment of the quality of evidence supporting these risk groups and identifying the most important risk groups is essential when making decisions about the allocation of influenza vaccination and antiviral therapy, and planning about health system utilisation. We summarised this evidence for seasonal and pandemic influenza.

\section{Methods}

All decisions regarding eligibility criteria, search strategy, study selection, assessment of risk for bias, explanations for heterogeneity, data collection, and analysis were established a priori.

\section{Eligibility criteria}

We included studies reporting on at least one risk factor-outcome combination in participants with evidence of influenza infection. The latter included laboratory confirmed influenza or the presence of influenza-like illness during a period of known influenza circulation. Studies on H5N1 avian influenza were considered but are not reported here. Eligible study designs included randomised controlled trials, cohort, case-control, and cross sectional. We included case series if participants with and without a specific outcome for a particular risk factor were reported, and we considered studies in English, French, German, Spanish, and Korean, based on the language skills of the study team. We excluded case reports.

\section{Outcomes}

Outcomes of interest included community acquired pneumonia, mortality, admission to hospital, admission to an intensive care unit, need for ventilator support, and any composites consisting of all or some of these outcomes. We chose these outcomes because they are patient important, most commonly reported in studies reporting on severe outcomes of influenza, and used for the clinical assessment in interventional studies on influenza. ${ }^{78}$

We defined community acquired pneumonia as involvement of the lower respiratory tract within 72 hours of hospital admission or according to the criteria in the original study. Ventilator support was defined as the need for respiratory support beyond applying oxygen alone.

\section{Risk factors}

We used the age categories that were most commonly reported in the original articles: $>65$ years for elderly, $<18$ years for children, 2 to $<5$ years, $<2$ years, and $<6$ months. If other categories were reported, we chose the closest to these cut-offs. We compared other ethnic groups with white participants. Definitions of comorbidities by the original studies were used. Obesity was defined as a body mass index of $>30 \mathrm{~kg} / \mathrm{m}^{2}$ or as defined by the original studies.

\section{Search strategy and data extraction}

We searched Medline, Embase, CINAHL, Global Health, and the Cochrane Central Register of Controlled Trials (CENTRAL) up to 25 March 2011. The search strategy was created in collaboration with a librarian (NB) and included a combination of keywords and subject headings for all major concepts (see supplementary appendix A). We also searched reference lists of identified articles and review articles.

We screened titles or abstracts and full text articles, extracted data using a standardised and piloted electronic database, and assessed risk of bias. Pairs of reviewers independently conducted all the steps. A third reviewer (DM) resolved any disagreement between reviewers by consensus or arbitration.

\section{Quality assessment}

We used the Newcastle-Ottawa scale to assess the risk of bias in observational studies. ${ }^{9}$ This scale allocates up to 9 points for the least risk of bias in four domains: selection of study groups (4 points), comparability of groups (2 points), and ascertainment of exposure and outcomes ( 3 points). Vaccination status for influenza and antiviral treatment were defined as the most important covariates that would define comparability.

We evaluated the quality of evidence for each risk factor using criteria selected from the grading of recommendations assessment, development, and evaluation (GRADE) framework. ${ }^{10}$ GRADE is a standardised approach to assess the quality of evidence, and ranges from very low to high. Two researchers (DM and JJ) independently assessed the GRADE of evidence by combining pandemic and seasonal influenza and considering all outcomes but giving additional weight to death.

\section{Meta-analyses}

Assuming that heterogeneity exists in findings across studies, we adopted a random effects model in Review Manager 5.0 (Cochrane Collaboration) $)^{11}$ to obtain a summary estimate of the average effect with its $95 \%$ confidence interval. ${ }^{12} \mathrm{We}$ used Stata/IC 11.2 (StataCorp LP, Texas, USA) to calculate the 95\% prediction intervals. The width of prediction intervals is affected by the uncertainty in the summary estimate and by the estimate (and its uncertainty) of the between-study standard deviation of the true effect, and prediction intervals are therefore affected by the heterogeneity across the studies. ${ }^{12}$

If risk estimates alone and no data were reported, we pooled the individual studies using the inverse variance method and converted to odds ratios and $95 \%$ confidence intervals in a secondary analysis. ${ }^{13} \mathrm{We}$ pooled case-control studies separately, whereas we included cross-sectional studies in the meta-analyses of cohort studies. Meta-analyses were performed overall and separately for pandemic and seasonal influenza. The $\mathrm{I}^{2}$ statistic was used to evaluate heterogeneity. ${ }^{14} \mathrm{We}$ explored heterogeneity between subgroups that were defined a priori (according to place of enrolment, risk of bias, laboratory confirmation of influenza, influenza vaccination status) whenever $\mathrm{I}^{2}$ was greater than $60 \%{ }^{15}$ The term used to define the place of enrolment included "community" (participants presenting in an outpatient setting at enrolment), "hospital" (participants admitted to hospital in a non-intensive care unit setting), and "intensive care unit" (participants admitted to hospital in the intensive care unit). Publication bias was assessed by visual interpretation of funnel plots and the Egger's test ${ }^{16}$ and, as a sensitivity analysis, with the test by Harbord. ${ }^{17}$

\section{Results}

We identified 63537 citations in the search of electronic databases and an additional 16 citations by searching bibliographies of relevant articles (figure $\Downarrow$ ). A total of 239 studies described in 234 articles met our eligibility criteria, comprising data on 610782 participants (table $2 \Downarrow$, see supplementary appendix B). The majority were cohort studies $(n=231,97 \%)$ that used laboratory confirmation to ascertain influenza infection $(n=220,92 \%)$ and most were conducted during pandemic influenza seasons $(n=183,77 \%)$. Since only six studies (3\% of all studies) with 1278 participants $(0.2 \%$ of the study population) were case-control studies, tables $3 \Downarrow$ and 
$4 \Downarrow$ present the results of only cohort studies. No studies included in the final synthesis needed to be excluded because of a failure to report either odds ratios and the $95 \%$ confidence intervals or raw data from which the odds ratios could be calculated. The summary estimates reported here were based on unadjusted risk estimates

\section{Risk of bias and quality of evidence assessment}

The Newcastle-Ottawa scale scores for risk of bias ranged from 1 to 8 out of a maximum of 9 , with a median of 6 across studies (table 2). Notably, adjusted risk estimates were provided for only 152 of 2788 (5.4\%) risk factor-outcome comparisons in 39 of $260(15 \%)$ studies. Because of the limited availability of adjusted risk estimates and the diversity of covariates adjusted for, meta-analyses of adjusted risk estimates were not conducted. However, when they were available, adjusted and crude odds ratio estimates were similar.

Based on an adaptation of the GRADE approach to assess the quality of evidence, our confidence in risk estimates was low for the presence of "any risk factor," obesity, any cardiovascular disease, and any neuromuscular disease, and very low for all other risk factors (table $5 \Downarrow$ ). All major risk factors with multiple studies were downgraded because of study quality, as their median Newcastle-Ottawa scale score was always below 7 . Inconsistency and imprecision were also common for most major risk factors (tables 3-5). For a given risk factor we would have expected consistency of associations with all outcomes. Thus, we considered heterogeneity in findings across outcomes within risk groups to be inconsistent using GRADE methodology as was heterogeneity across studies for each risk factor-outcome combination.

While the presence of heterogeneity and the small number of studies for each risk factor-outcome comparison limited the ability to assess the risk of publication bias, there was no convincing evidence of publication bias for the risk factor-mortality combinations that were deemed to be at low level of evidence. The presence of publication bias would not have further decreased the level of evidence for risk factors already deemed to be very low.

\section{Seasonal influenza}

\section{Age as a risk factor}

We found a significant increase in the risk of death among elderly people compared with non-elderly people (odds ratio $2.95,95 \%$ confidence interval 1.53 to $5.70, \mathrm{I}^{2}=11 \%, \mathrm{n}=4$ ) (table 3). Elderly participants also had a higher risk of admission to hospital. Children aged less than 5 years were at lower risk of death $\left(0.40,0.20\right.$ to $\left.0.80, \mathrm{I}^{2}=0 \%, \mathrm{n}=8\right)$, had lower hospital admission rates, and were less likely to need ventilator support than older children but were at higher risk of developing pneumonia. When very young children $(<2$ years of age $)$ were compared with the other age groups, they were at significantly lower risk for admission to hospital, admission to an intensive care unit, and the need for ventilator support.

\section{Ethnicity and pregnancy}

Data on ethnicity was rare for seasonal influenza, and no ethnicity studied was associated with a significant higher risk for severe outcomes. In contrast with pandemic influenza, pregnancy as a risk factor was not well studied for seasonal influenza, with only one study having data on this with no significant association with death.

\section{Comorbidity}

Based largely on comorbidity, the presence of "any risk factor" was significantly associated with death $(2.04,1.74$ to 2.39 , $\mathrm{I}^{2}=0 \%, \mathrm{n}=4$ ), pneumonia, hospital admission, and admission to an intensive care unit. Only one seasonal influenza study with a small event rate provided data on obesity as a risk factor, which showed an increased risk of death $(30.1,1.17$ to 773.12$)$.

The presence of chronic lung disease was associated with a higher risk for admission to hospital and to an intensive care unit, and the need for ventilator support. Asthma was only associated with a higher risk of developing pneumonia, whereas chronic obstructive pulmonary disease was associated with a higher likelihood of needing ventilator support. Cardiovascular disease increased the risk of death $\left(1.97,1.06\right.$ to $3.67, \mathrm{I}^{2}=46 \%$, $\mathrm{n}=8$ ) as well as of pneumonia, hospital admission, and need for ventilator support. Immunocompromised participants were at higher risk for death $\left(3.81,1.28\right.$ to $\left.11.35, \mathrm{I}^{2}=71 \%, \mathrm{n}=4\right)$ but at lower risk of developing pneumonia. The presence of any neuromuscular disease was associated with a higher risk for death $\left(3.21,1.84\right.$ to $\left.5.58, \mathrm{I}^{2}=0 \%, \mathrm{n}=4\right)$, whereas diabetes mellitus but not any of the other risk factors of interest was associated with a higher risk for hospital admission.

\section{Pandemic influenza}

\section{Age as a risk factor}

Elderly people were at higher risk for death compared with younger adults during pandemic influenza $(2.69,1.53$ to 4.71 , $\mathrm{I}^{2}=86 \%, \mathrm{n}=29$ studies) (table 4 ). The summary estimate was even greater when only community based studies were pooled (6.35, 1.26 to $\left.31.94, I^{2}=93 \%, n=5\right)$. However, there was a large overlap in the $95 \%$ confidence interval across subgroups, specifically: 1.26 to $31.94\left(\mathrm{I}^{2}=93 \%, \mathrm{n}=4\right)$ in the community and 2.24 to $5.48\left(I^{2}=68 \%, n=16\right)$ in participants admitted to hospital. Similarly there was overlap between $95 \%$ prediction intervals in these settings: 0.01 to 2900 in the community and 0.87 to 14.07 in participants admitted to hospital. Elderly participants were also at higher risk for hospital admission but at lower risk of being admitted to the intensive care unit.

In contrast, the risk of death in children (compared with non-elderly adults) was reduced $(0.28,0.19$ to $0.41,95 \%$ prediction interval 0.09 to $0.82, \mathrm{I}^{2}=39 \%, \mathrm{n}=21$ ). Again, the effect was accentuated in community based studies $(0.19,0.10$ to 0.36 , $\left.\mathrm{I}^{2}=39 \%, \mathrm{n}=4\right)$, but with overlapping $95 \%$ prediction intervals ( 0.02 to 1.49 in the community, 0.08 to 0.84 in the hospital, and 0.28 to 0.72 in the intensive care unit setting). Children aged less than 5 years were at a higher risk of developing pneumonia and requiring hospital admission but tended to be at lower risk of death $\left(0.59,0.29\right.$ to $\left.1.22, \mathrm{I}^{2}=49 \%, \mathrm{n}=15\right)$ and were at a lower risk for admission to an intensive care unit. Compared with non-elderly adults, children were less likely to be admitted to hospital with pandemic influenza.

\section{Ethnicity}

Despite the availability of a larger number of studies for pandemic influenza than for seasonal influenza addressing ethnicity as a potential risk factor, we found no significant differences in all cause mortality among Asian, black, or native populations compared with white participants. The only significant difference was a higher risk for hospital admission for black and Hispanic participants but a lower risk for admission to an intensive care unit for black participants. For Australian natives, the likelihood of hospital admission was lower compared with white participants. 


\section{Pregnancy}

Pregnancy did not increase the risk of death. However, pregnant women were at higher risk for hospital admission but were not at increased risk of pneumonia and, in fact, were at significantly reduced risk of admission to an intensive care unit. In contrast, women who were less than four weeks post partum had a significantly increased risk of death $(4.43,95 \%$ confidence interval 1.24 to $15.81, \mathrm{I}^{2}=0 \%, \mathrm{n}=3$ ). When compared with those in the first or second trimester, women in the third trimester had an increase in all cause mortality $\left(1.22,1.01-1.48, \mathrm{I}^{2}=0 \%, \mathrm{n}=5\right)$.

\section{Comorbidity}

The presence of "any risk factor" was associated with higher all cause mortality $\left(2.77,1.90\right.$ to $\left.4.05, \mathrm{I}^{2}=88 \%, \mathrm{n}=53\right)$ and also with higher admission rates to hospital and an intensive care unit. Reports on obesity as a risk factor from 59 studies showed that obesity not only increased the risk of death $(2.74,1.56$ to $4.80, I^{2}=92 \%, n=33$ ) but was significantly associated with the need for admission to hospital and an intensive care unit, as well as for ventilator support.

The presence of any chronic lung disease $(1.71,1.17$ to 2.51 , $\left.\mathrm{I}^{2}=79 \%, \mathrm{n}=27\right)$, chronic obstructive pulmonary disease (1.49, 1.15 to $\left.1.92, \mathrm{I}^{2}=0 \%, \mathrm{n}=13\right)$, or obstructive sleep apnoea $(2.63$, 1.25 to $5.52, \mathrm{I}^{2}=0 \%, \mathrm{n}=2$ ) also increased the risk for death. We also found associations between the presence of any chronic lung disease and admission to hospital as well as admission to an intensive care unit, and between chronic obstructive pulmonary disease and admission to an intensive care unit. Cardiovascular disease increased the risk of death significantly (2.92, 1.76 to $\left.4.86, \mathrm{I}^{2}=89 \%, \mathrm{n}=28\right)$. We also found an association with admission to hospital and an intensive care unit. In contrast with seasonal influenza, hypertension was associated with a higher risk for death $\left(1.49,1.10\right.$ to $\left.2.10, \mathrm{I}^{2}=0 \%, \mathrm{n}=7\right)$.

Immunosuppression increased the risk of death from pandemic influenza $\left(3.67,1.78\right.$ to $\left.7.58, \mathrm{I}^{2}=94 \%, \mathrm{n}=23\right)$, and immunocompromised participants were more likely to be admitted to hospital. Participants with malignancy $(3.10,2.35$ to $4.10, \mathrm{I}^{2}=0 \%, \mathrm{n}=12$ for mortality) and neuromuscular disease had an increased risk of death $\left(2.68,1.91\right.$ to $\left.3.75, \mathrm{I}^{2}=25 \%, \mathrm{n}=16\right)$. Neurocognitive diseases were not significantly associated with death but were with admission to hospital and an intensive care unit and with ventilator support. Further risk factors found to be associated with a higher risk of death included anaemia or haemoglobinopathy, diabetes mellitus, and liver, metabolic, and renal disease (table 4).

\section{Heterogeneity}

In most instances heterogeneity was due to differences in magnitude rather than a different direction of the effect. Risk estimates were typically highest in the community based populations, lower in participants admitted to hospital, and lowest in participants admitted to an intensive care unit, both across studies in the meta-analysis and within studies. One example was the presence of "any risk factor" for total mortality: the study by Buda et $\mathrm{al}^{18}$ showed an odds ratio of 72.48 (95\% confidence interval 50.35 to 104.33 ) in the overall community sample but only 19.18 (13.26 to 27.73 ) in the subgroup of participants who needed hospital admission. In our meta-analysis, we found an odds ratio of 10.06 (2.32 to 43.61, $\left.\mathrm{I}^{2}=86 \%, \mathrm{n}=9\right)$ in the community, 3.01 (2.01 to $4.51, \mathrm{I}^{2}=85 \%$, $\mathrm{n}=30$ ) in participants admitted to hospital, and 1.56 (1.28 to $\left.1.90, \mathrm{I}^{2}=9 \%, \mathrm{n}=22\right)$ in participants admitted to an intensive care unit. However, when considering the $95 \%$ prediction intervals, there was a large overlap across the subgroups (0.08 to 1287.99 ,
0.50 to 17.97 , and 1.09 to 2.21 , respectively). Other than stratification by population, our hypotheses to explain heterogeneity were of limited value: data on vaccination was often lacking, rendering subgrouping impossible, only a few studies did not use laboratory confirmation of influenza, and subgrouping by risk of bias was not helpful because most studies $(n=196,75 \%)$ were in the middle range of risk of bias (4-6 Newcastle-Ottawa scale points).

Only a few risk factors were associated, significantly or at least in a trend, with all outcomes of interest for both types of influenza (table 5). With the exception of pneumonia in studies during pandemic influenza, these included the presence of "any risk factor," obesity, and neuromuscular diseases. Chronic lung diseases were associated with all outcomes other than pneumonia and ventilator support during pandemic influenza.

Cardiovascular diseases were associated with all outcomes other than pneumonia during pandemic influenza and admission to an intensive care unit during seasonal influenza. Neurocognitive disease was not associated with all cause mortality during seasonal influenza, but was with all other outcomes with data available.

\section{Discussion}

The evidence supporting risk factors for severe outcomes of influenza ranges from being limited to absent. This was particularly relevant in the relative lack of data for studies on non-2009 H1N1 pandemics and for seasonal influenza. The level of evidence was low for "any risk factor," obesity, cardiovascular diseases, and neuromuscular disease, and was very low for all other risk factors.

\section{Why the evidence was limited}

There were widely accepted risk factors, such as pregnancy, as well as more recently described risks, such as belonging to an ethnic minority group, for which we could not find a trend for higher rates of severe outcomes other than more frequent hospital admission. Given the lack of a demonstrable effect for these comparisons despite large sample sizes, lack of power is an unlikely explanation. On the other hand, we found positive effects that did not reach statistical significance in some risk factor-outcome comparisons for which there were only small sample sizes. For example, the association between chronic lung diseases and mortality during seasonal influenza (odds ratio 1.8, $95 \%$ confidence interval 0.81 to 4.01 ) was not statistically significant. Calculating the optimal information size ${ }^{19}$ with consideration of the heterogeneity found for this comparison, ${ }^{20}$ approximately 5000 participants would have been required in each arm to detect a difference of $25 \%$ in mortality. Given that only 1200 participants were available, the lack of statistical significance was most likely due to a lack of power. Because influenza vaccination was not adjusted for, the calculated risk estimates may have underestimated the true effect size-for example, because chronic lung disease is a well known risk factor, participants with chronic lung diseases may have been more likely to be vaccinated than the comparison group thus mitigating the risk for severe outcomes in participants with underlying chronic lung disease. We also found that such a lack of adjustment for confounders was widespread: adjusted risk estimates were provided for only $5.4 \%$ of risk factor-outcome comparisons in 39 of 260 (15\%) studies. Although such a lack of adjusted risk estimates could potentially be misleading, we did find similar effect sizes in those studies that reported both adjusted and unadjusted risk estimates. 
The relative lack of eligible studies on non-H1N1 pandemic influenza and on seasonal influenza before 1991 was surprising. Therefore the findings from the meta-analyses on pandemic influenza cannot necessarily be extrapolated to non-H1N1 pandemic strains, and the findings on seasonal influenza cannot necessarily be extrapolated to non-H3N2 and non-influenza B strains.

Variability in definitions of risk factors and the potential for differential ascertainment of risk factors possibly contributed to the heterogeneity in the affected comparisons. Differing lengths of follow-up may have also resulted in heterogeneity, and studies that were deemed to have an inadequate length of follow-up (16\%) may have missed events and therefore biased the results towards smaller effect sizes. Owing to the differing length of follow-up used in the included studies, meta-analysis of hazard ratios instead of odds ratios might have reduced heterogeneity. In contrast with odds ratios, hazard ratios are more likely to be constant over time. ${ }^{21}$ Unfortunately, hazard ratios were rarely reported and thus meta-analysis of hazard ratios was not feasible. Another limitation of the data was inconsistency in outcomes - that is, for a given risk factor we would have expected to see an increase in all types of severe outcomes. Thus when evaluating risk factors with inconsistent findings across outcomes, we downgraded the level of evidence.

The presence of poor quality of evidence in studies on prognostic factors in general is well known ${ }^{22}$; we found a similar picture for risk factors for severe outcomes with influenza in our study, despite the important public health implications of these studies.

\section{Interpretation of meta-analysis results}

Our meta-analysis showed that elderly people had the highest risk of death during both seasonal and pandemic influenza seasons. In contrast, children and young people aged less than 18 years had a significantly reduced risk of death compared with non-elderly adults during pandemics. Children aged less than 5 years, in particular those aged 2 to less than 5 years, were at increased risk of pneumonia from both pandemic and seasonal influenza when compared with older children. ${ }^{2324}$ Age less than 2 years was not a risk factor for any outcome other than hospital admission during pandemic influenza.

Pregnancy increased the risk of admission to hospital but not for any of the other outcomes. In contrast, women in the postpartum period were at higher risk for severe outcomes. ${ }^{25} 26$ In studies comparing the third trimester of pregnancy with the first and second trimesters, the third trimester placed women at higher risk of severe outcomes. ${ }^{27}{ }^{28}$ These data suggest that risk increases in the late stages of pregnancy. ${ }^{29}{ }^{30}$ Notably, the results of ongoing systematic reviews on adverse effects, outcomes, and effectiveness of influenza vaccination in pregnancy will be of interest. ${ }^{3132}$ Our findings are in keeping with recommendations to prioritise vaccination of pregnant women because of the increased risk for mortality post partum, and elderly people. In contrast, we did not found convincing evidence to prioritise vaccination of young children compared with adults.

Our findings also suggest that obesity (body mass index $>30$ ) is an important cause of death with both pandemic and seasonal influenza. ${ }^{28}{ }^{33}$ It remains unclear whether obesity in itself is a risk factor or whether it reflects the presence of other comorbidities such as cardiovascular diseases and diabetes mellitus. ${ }^{34}$ However, morbid obesity was identified as a potential independent risk factor after adjustment for these comorbidities. ${ }^{33}$
It has been suggested that certain ethnic groups may have been at higher risk for severe outcomes due to influenza during the 2009 pandemic $^{30}$; however, we found no significant differences in all cause mortality among Asian, black, or native populations compared with white participants for either seasonal or pandemic influenza. ${ }^{28-36}$ Hispanic and black participants as well as pregnant women were more likely to have been admitted to hospital during the $2009 \mathrm{H} 1 \mathrm{~N} 1$ pandemic but were at lower risk for more severe outcomes. ${ }^{28}{ }^{37}$ It may be that because of a perception among healthcare providers of an increased risk of complications that these groups were selectively admitted to hospital during the 2009 H1N1 pandemic. This is in contrast with seasonal influenza where people of Hispanic ancestry were almost half as likely to be admitted to hospital.

As expected, chronic illness, including immunosuppression, cardiovascular disease, chronic lung disease, neuromuscular disease, neurological disease, chronic renal disease, and metabolic diseases increased the risk of mortality from influenza. Mortality did not differ among the sexes.

We found slightly greater effect sizes in community based studies compared with hospital based and intensive care unit based studies. We speculate that this is because heterogeneity among participants in community based studies is greater than among participants admitted to hospital - that is, participants admitted to hospital may share a level of comorbidity that, apart from the risk factor in question, leads to more similar outcomes. ${ }^{38}$ An overlap did occur in the prediction intervals in these instances, either due to heterogeneity or due to the small number of studies available. It thus remains uncertain whether these differences were due to chance alone.

\section{Strengths and limitations of this review}

Strengths of this review were the comprehensive search strategy, the extensive amount of data reviewed, the assessment for study quality, the high percentage of studies using laboratory confirmation to diagnose influenza, and the breadth of outcomes and risk factors examined. In addition to the limitations of the included studies, it should be noted that the GRADE methodology used was developed to assess quality of evidence for interventions and not for prognostic factors. Therefore it remains unclear whether similar standards need to apply to the types of studies in this review because randomised controlled trials on risk factors are not feasible and therefore a high level of evidence according to GRADE methodology is unlikely ever to be achieved. ${ }^{10}$

\section{Implications of the findings}

Policy makers and public health organisations such as WHO should acknowledge the poor quality of evidence supporting vaccine recommendations for those deemed to be at high risk from influenza and to outline the level of evidence in their vaccination recommendations. This is of particular relevance when vaccine supply is insufficient. Obesity and the postpartum period were identified as potentially important risk factors that should be included in future vaccination recommendations. Given the limited level of evidence, however, any well designed and adequately powered and conducted study is likely to affect the conclusions of this systematic review. This being said, our findings highlight the importance of conducting rigorous studies and of adequately reporting the results when assessing complications due to influenza.

We thank Stephen Walter for his comments and edits. 


\section{What is already known on this topic}

Certain patient populations are thought to be at higher risk for developing complicated or severe influenza illness

These groups are prioritised for vaccination as well as for antiviral treatment

\section{What this study adds}

The quantity and quality of evidence on risk factors for developing complicated or severe influenza illness is limited While some risk factors could be corroborated, evidence to support other, well established risk factors for severe outcomes could not be found

Contributors: All authors were involved in the conception and design of the study and the interpretation of data. DM and ML were responsible for the analysis and drafting of the article. All authors revised the manuscript critically for important intellectual content, gave final approval of the version to be published, had full access to all data in the study, and take responsibility for the integrity of the data and the accuracy of the data analysis. DM and $\mathrm{ML}$ are guarantors.

Funding: This systematic review was funded by WHO as part of an ongoing process of reviewing and revising current $\mathrm{WHO}$ recommendations. The protocol for the review was discussed with WHO and its suggestions were incorporated into the protocol.

Competing interests: All authors have completed the ICMJE uniform disclosure form at www.icmje.org/coi_disclosure.pdf and declare that: DM was partly supported by a research scholarship from the Swiss National Science Foundation (PASMP3-132571) and the Lichtenstein-Stiftung and is a recipient of a research early career award from Hamilton Health Sciences Foundation (Jack Hirsh Fellowship); ML holds the Michael G DeGroote chair in infectious diseases at McMaster University; JJ receives salary support from the Canadian Institutes of Health Research; ML has been a paid consultant for GlaxoSmithKline, Novartis, and Sanofi Pasteur (vaccine manufacturers); all other authors have no relationships with companies that might have an interest in the submitted work in the previous three years; spouses, partners, or children of the authors have no financial relationship that may be relevant to the submitted work; all authors have no non-financial interests that may be relevant to the submitted work.

Ethical approval: Not required.

Data sharing: No additional data available.

1 World Health Organization. Fact sheet on influenza. 2009. www.who.int/mediacentre/ factsheets/fs211/en/index.html.

2 Center for Disease Control and Prevention. People at high risk of developing flu-related complications. 2012. www.cdc.gov/flu/index.htm.

3 Dawood FS, luliano AD, Reed C, Meltzer MI, Shay DK, Cheng PY, et al. Estimated global mortality associated with the first 12 months of 2009 pandemic influenza A H1N1 virus circulation: a modelling study. Lancet Infect Dis 2012;12:687-95.

4 Fiore AE, Uyeki TM, Broder K, Finelli L, Euler GL, Singleton JA, et al. Prevention and control of influenza with vaccines: recommendations of the Advisory Committee on Immunization Practices (ACIP), 2010. MMWR Recomm Rep 2010;59(RR-8):1-62.

5 World Health Organization. Strategic Advisory Group of Experts (SAGE) meeting of April 2012. www.who.int/influenza/vaccines/SAGE_information/en/index.html.

6 Strategic Advisory Group of Experts on Immunization-report of the extraordinary meeting on the influenza A (H1N1) 2009 pandemic, 7 July 2009. Wkly Epidemiol Rec 2009;84:301-4.

7 Michiels B, Van Puyenbroeck K, Verhoeven V, Vermeire E, Coenen S. The value of neuraminidase inhibitors for the prevention and treatment of seasonal influenza: a systematic review of systematic reviews. PLoS One 2013;8:e60348.

8 Hsu J, Santesso N, Mustafa R, Brozek J, Chen YL, Hopkins JP, et al. Antivirals for treatment of influenza: a systematic review and meta-analysis of observational studies. Ann Intern Med 2012:156:512-24.

9 Wells GA, Shea B, O'Connell D, Peterson J, Welch V, Losos M, et al. The Newcastle-Ottawa Scale (NOS) for assessing the quality of nonrandomised studies in meta-analyses. 2011. www.ohri.ca/programs/clinical_epidemiology/oxford.asp.

10 Atkins D, Best D, Briss PA, Eccles M, Falck-Ytter Y, Flottorp S, et al. Grading quality of evidence and strength of recommendations. BMJ 2004;328:1490.

11 DerSimonian R, Laird N. Meta-analysis in clinical trials. Control Clin Trials 1986;7:177-88.

12 Riley RD, Higgins JP, Deeks JJ. Interpretation of random effects meta-analyses. BMJ 2011;342:d549.

13 Zhang J, Yu KF. What's the relative risk? A method of correcting the odds ratio in cohort studies of common outcomes. JAMA 1998;280:1690-1.

14 Higgins JP, Thompson SG, Deeks JJ, Altman DG. Measuring inconsistency in meta-analyses. BMJ 2003;327:557-60.
15 Higgins JPT, Green S, editors. Cochrane Handbook for Systematic Reviews of Interventions. Version 5.1.0 [updated March 2011]. In: The Cochrane Collaboration, 2011. www.cochrane-handbook.org.

16 Egger M, Davey Smith G, Schneider M, Minder C. Bias in meta-analysis detected by a simple, graphical test. BMJ 1997;315:629-34.

17 Harbord RM, Egger M, Sterne JA. A modified test for small-study effects in meta-analyses of controlled trials with binary endpoints. Stat Med 2006;25:3443-57.

18 Buda S, Kopke K, Haas W. [Epidemiological characteristics of the influenza pandemic (H1N1) 2009 in Germany based on the mandatory notification of cases]. Bundesgesundheitsblatt Gesundheitsforschung Gesundheitsschutz 2010;53:1223-30

19 Guyatt GH, Oxman AD, Kunz R, Brozek J, Alonso-Coello P, Rind D, et al. GRADE guidelines 6. Rating the quality of evidence-imprecision. J Clin Epidemiol 2011;64:1283-93.

20 Thorlund K, Imberger G, Walsh M, Chu R, Gluud C, Wetterslev J, et al. The number of patients and events required to limit the risk of overestimation of intervention effects in meta-analysis-a simulation study. PLoS One 2011;6:e25491.

21 Perneger TV. Estimating the relative hazard by the ratio of logarithms of event-free proportions. Contemp Clin Trials 2008;29:762-6.

22 Riley RD, Hayden JA, Steyerberg EW, Moons KG, Abrams K, Kyzas PA, et al. Prognosis Research Strategy (PROGRESS) 2: prognostic factor research. PLOS Med 2013;10:e1001380.

23 Dawood FS, Fiore A, Kamimoto L, Nowell M, Reingold A, Gershman K, et al. Influenza-associated pneumonia in children hospitalized with laboratory-confirmed influenza, 2003-2008. Pediatr Infect Dis J 2010;29:585-90

24 Stein M, Tasher D, Glikman D, Shachor-Meyouhas Y, Barkai G, Yochai AB, et al. Hospitalization of children with influenza A(H1N1) virus in Israel during the 2009 outbreak in Israel: a multicenter survey. Arch Pediatr Adolesc Med 2010;164:1015-22.

25 Louie JK, Acosta M, Jamieson DJ, Honein MA, California Pandemic Working G. Severe 2009 H1N1 influenza in pregnant and postpartum women in California. N Engl J Med 2010;362:27-35.

26 Xi X, Xu Y, Jiang L, Li A, Duan J, Du B, et al. Hospitalized adult patients with 2009 influenza A(H1N1) in Beijing, China: risk factors for hospital mortality. BMC Infect Dis 2010;10:256.

27 Dubar G, Azria E, Tesniere A, Dupont H, Le Ray C, Baugnon T, et al. French experience of 2009 A/H1N1v influenza in pregnant women. PLoS One 2010;5: pii: e13112.

28 Siston AM, Rasmussen SA, Honein MA, Fry AM, Seib K, Callaghan WM, et al. Pandemic 2009 influenza $\mathrm{A}(\mathrm{H} 1 \mathrm{~N} 1)$ virus illness among pregnant women in the United States. JAMA 2010;303:1517-25

29 Neuzil KM, Reed GW, Mitchel EF, Simonsen L, Griffin MR. Impact of influenza on acute cardiopulmonary hospitalizations in pregnant women. Am J Epidemiol 1998;148:1094-102.

30 Van Kerkhove MD, Vandemaele KA, Shinde V, Jaramillo-Gutierrez G, Koukounari A, Donnelly CA, et al. Risk factors for severe outcomes following 2009 influenza A (H1N1) infection: a global pooled analysis. PLOS Med 2011;8:e1001053.

31 Fell DB, Platt R. Pregnancy outcomes associated with maternal influenza vaccination: systematic review and meta-analysis. 2013. www.crd.york.ac.uk/PROSPERO/display record.asp?ID=CRD42013004135\#.Uc20pfnVCSo.

32 McMillan M, Kralik D, Porritt K, Marshall $\mathrm{H}$. Influenza vaccination during pregnancy: a systematic review of effectiveness and adverse effects. 2013. www.crd.york.ac.uk/ PROSPERO/display_record.asp?ID=CRD42012003235\#.Uc21t_nVCSo.

33 Louie JK, Acosta M, Samuel MC, Schechter R, Vugia DJ, Harriman K, et al. A novel risk factor for a novel virus: obesity and 2009 pandemic influenza A (H1N1). Clin Infect Dis 2011;52:301-12.

34 Flegal KM, Graubard BI, Williamson DF, Gail MH. Excess deaths associated with underweight, overweight, and obesity. JAMA 2005;293:1861-7.

35 Campbell A, Rodin R, Kropp R, Mao Y, Hong Z, Vachon J, et al. Risk of severe outcomes among patients admitted to hospital with pandemic (H1N1) influenza. CMAJ 2010;182:349-55.

36 Helferty M, Vachon J, Tarasuk J, Rodin R, Spika J, Pelletier L. Incidence of hospital admissions and severe outcomes during the first and second waves of pandemic (H1N1) 2009. CMAJ 2010;182:1981-7.

37 Byington CL, Pavia AT, Rajendu S, Bender JM, Ampofo K, Gesteland P, et al. Development and validation of a risk score for predicting hospitalization in children with influenza virus infection. Pediatr Emerg Care 2009;25:369-75.

38 Neupane B, Walter SD, Krueger P, Loeb M. Community controls were preferred to hospital controls in a case-control study where the cases are derived from the hospital. J Clin Epidemiol 2010;63:926-31.

Accepted: 22 July 2013

\section{Cite this as: BMJ 2013:347:f5061}

This is an Open Access article distributed in accordance with the Creative Commons Attribution Non Commercial (CC BY-NC 3.0) license, which permits others to distribute, remix, adapt, build upon this work non-commercially, and license their derivative works on different terms, provided the original work is properly cited and the use is non-commercial. See: http://creativecommons.org/licenses/by-nc/3.0/. 


\section{Tables}

\section{Table 1| Current World Health Organization and Center for Disease Control and Prevention (CDC) recommendations for influenza vaccination}

\begin{tabular}{|c|c|c|c|}
\hline \multirow[b]{2}{*}{ Groups } & \multicolumn{2}{|c|}{ WHO } & \multirow{2}{*}{$\begin{array}{c}\text { CDC } \\
\text { Seasonal } 2011^{2}\end{array}$} \\
\hline & Pandemic $2009^{6}$ & Seasonal $2012^{5}$ & \\
\hline Healthcare workers & 1 & Recommended & Recommended \\
\hline Pregnant women & 2 & 1 & Recommended \\
\hline Aged >6 months with "chronic medical conditions" & 3 & Recommended & - \\
\hline $\begin{array}{l}\text { Aged }>6 \text { months with specific chronic medical } \\
\text { conditions }\end{array}$ & - & - & Recommended \\
\hline $\begin{array}{l}\text { Aged } 6 \text { months to } 18 \text { years and receiving long term } \\
\text { aspirin treatment }\end{array}$ & - & - & Recommended \\
\hline \multicolumn{4}{|l|}{ Healthy people: } \\
\hline Young children (6-59 months) & - & Recommended & Recommended \\
\hline Healthy children & 5 & - & - \\
\hline Young adults ( $>15$ and $<49$ years) & 4 & - & - \\
\hline Adults ( $>40$ and $<65$ years) & 6 & - & - \\
\hline Adults ( $\geq 50$ years) & - & - & Recommended \\
\hline Adults (>65 years) & 7 & Recommended & - \\
\hline $\begin{array}{l}\text { Residents of nursing homes and other chronic care } \\
\text { facilities }\end{array}$ & - & - & Recommended \\
\hline American Indians/Alaska Natives & - & - & Recommended \\
\hline Morbidly obese (body mass index $\geq 40$ ) & - & - & Recommended \\
\hline $\begin{array}{l}\text { Household contacts and caregivers of children aged } \\
<5 \text { years and adults aged } \geq 50 \text { years or of people with } \\
\text { high risk conditions }\end{array}$ & - & - & Recommended \\
\hline
\end{tabular}

Numbers indicate priority level (where applicable), recommended indicates vaccination recommendation.

CDC recommends routine vaccination of all individuals aged 6 months and older. The table summarises groups prioritised by CDC in the setting of limited vaccine supply.

${ }^{*}$ Chronic pulmonary including asthma, cardiovascular except hypertension, renal, hepatic, neurological, haematological, metabolic including diabetes mellitus, immunosuppressed. 
Table 2/ Study characteristics of 239 studies in 234 included articles. Values are numbers (percentages) unless stated otherwise

\begin{tabular}{|c|c|c|c|}
\hline Characteristics & Overall & Pandemic influenza & Seasonal influenza \\
\hline Range of publication year & $1918-2011$ & $1918-2011$ & $1970-2011$ \\
\hline No of studies & 239 & 183 & 56 \\
\hline \multicolumn{4}{|l|}{ Pandemic influenza: } \\
\hline 1918/1919 H1N1 & NA & $3(2)$ & NA \\
\hline 1957/1958 H2N2 & NA & $3(2)$ & NA \\
\hline 1968/1969 H3N2 & NA & $1(0.5)$ & NA \\
\hline 1977/1978 H1N1 & NA & $1(0.5)$ & NA \\
\hline 2009/2010 H1N1 & NA & $175(96)$ & NA \\
\hline \multicolumn{4}{|l|}{ Seasonal influenza: } \\
\hline $1961-70$ & NA & NA & $1(2)$ \\
\hline $1971-80$ & NA & NA & $3(5)$ \\
\hline $1981-90$ & NA & NA & $4(7)$ \\
\hline $1991-2000$ & NA & NA & $15(27)$ \\
\hline $2001-10$ & NA & NA & $33(59)$ \\
\hline No of participants & 610782 & 534911 & 75871 \\
\hline English articles & $223(93)$ & $171(93)$ & $52(93)$ \\
\hline \multicolumn{4}{|l|}{ Geographical region: } \\
\hline North America & $82(34)$ & $50(27)$ & $32(57)$ \\
\hline Europe & $58(24)$ & $49(27)$ & $9(16)$ \\
\hline Central/South America & $25(10)$ & $24(13)$ & $1(2)$ \\
\hline Asia & $49(21)$ & $39(21)$ & $10(18)$ \\
\hline Others & $25(10)$ & $21(12)$ & $4(7)$ \\
\hline Cohort studies & $231(97)$ & $175(96)$ & $56(100)$ \\
\hline Laboratory confirmation of influenza & $220(92)$ & $173(95)$ & $47(84)$ \\
\hline \multicolumn{4}{|c|}{ Median (range) Newcastle-Ottawa scale points: } \\
\hline Overall & $6(1-8)$ & $6(1-8)$ & $6(3-8)$ \\
\hline Selection of study groups & $3(1-4)$ & $3(1-4)$ & $3(2-4)$ \\
\hline Comparability of groups & $0(0-1)$ & $0(0-1)$ & $0(0-1)$ \\
\hline Ascertainment of diseases & $3(0-3)$ & $3(0-3)$ & $3(0-3)$ \\
\hline
\end{tabular}

$\mathrm{NA}=$ not applicable.

If reporting across more than one 10 year band, the band with the most participants was chosen. 


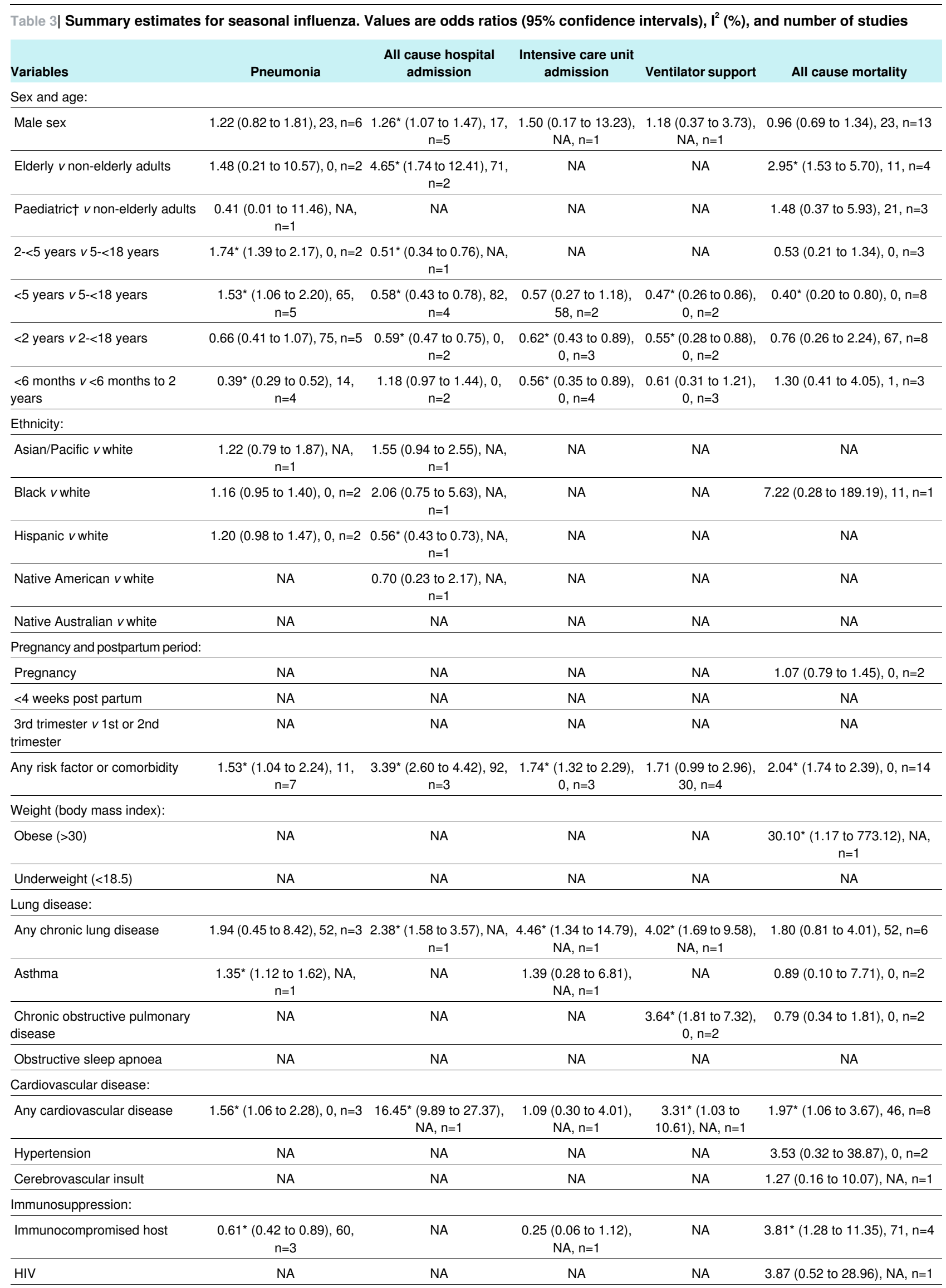


Table 3 (continued)

\begin{tabular}{|c|c|c|c|c|c|}
\hline Variables & Pneumonia & $\begin{array}{l}\text { All cause hospital } \\
\text { admission }\end{array}$ & $\begin{array}{l}\text { Intensive care unit } \\
\text { admission }\end{array}$ & Ventilator support & All cause mortality \\
\hline Chronic steroid therapy & NA & $\begin{array}{l}\left.17.49^{*} \text { (6.97 to } 43.92\right) \\
\text { NA, } n=1\end{array}$ & NA & NA & 1.79 (0.66 to 4.87$), N A, n=1$ \\
\hline Malignancy & $\begin{array}{c}1.19(0.51 \text { to } 2.77), N A \text {, } \\
n=1\end{array}$ & $\begin{array}{c}19.35^{*}(10.55 \text { to } 35.48) \\
\text { NA, } n=1\end{array}$ & NA & NA & $2.67(0.22$ to 32.23$), N A, n=1$ \\
\hline \multicolumn{6}{|l|}{ Neurological disease: } \\
\hline Any neuromuscular disease & $\begin{array}{c}1.57 \text { (1.05 to } 2.36), N A \text {, } \\
n=1\end{array}$ & NA & NA & NA & $3.21^{*}$ (1.84 to 5.58$), 0, n=4$ \\
\hline Neurocognitive disease & $\begin{array}{l}1.45^{\star}(1.05 \text { to } 1.99), N A \\
n=1\end{array}$ & NA & $\begin{array}{c}2.07(0.75 \text { to } 5.72) \\
N A, n=1\end{array}$ & NA & 1.33 ( 0.33 to 5.33$), 0, n=2$ \\
\hline Seizure & $\begin{array}{c}0.99(0.70 \text { to } 1.40), N A \text {, } \\
n=1\end{array}$ & NA & NA & NA & 6.53 (0.24 to 177.39$), N A, n=1$ \\
\hline \multicolumn{6}{|l|}{ Other risk factors: } \\
\hline $\begin{array}{l}\text { Alcohol with or without illicit drug } \\
\text { use }\end{array}$ & $\begin{array}{c}0.47(0.07 \text { to } 2.96), N A \text {, } \\
n=1\end{array}$ & NA & NA & NA & $0.13(0.01$ to 2.34$), N A, n=1$ \\
\hline Anaemia or haemoglobinopathy & $\begin{array}{c}0.54(0.34 \text { to } 0.84), N A \text {, } \\
n=1\end{array}$ & NA & $\begin{array}{c}0.12(0.01 \text { to } 1.99) \\
\text { NA, } n=1\end{array}$ & NA & NA \\
\hline Autoimmune disease & NA & NA & NA & NA & NA \\
\hline Diabetes mellitus & $0.91(0.26$ to 3.24$), 0, n=2$ & $\begin{array}{c}\left.9.91^{*} \text { (5.46 to } 17.99\right) \\
\text { NA, } n=1\end{array}$ & NA & NA & $0.59(0.23$ to 1.50$), 0, n=2$ \\
\hline Endocrinological disease & NA & NA & NA & NA & $\begin{array}{c}\left.13.92^{*} \text { (3.71 to } 52.13\right), \mathrm{NA}, \\
\mathrm{n}=1\end{array}$ \\
\hline Gastrointestinal disease & NA & NA & NA & NA & NA \\
\hline Liver disease & NA & NA & NA & NA & 0.38 (0.04 to 3.98$), N A, n=1$ \\
\hline Metabolic disease & $\begin{array}{c}0.89(0.53 \text { to } 1.50), N A \text {, } \\
n=1\end{array}$ & NA & NA & NA & $0.52(0.12$ to 2.21$), N A, n=1$ \\
\hline Prematurity or preterm birth & NA & NA & NA & NA & NA \\
\hline Renal disease & 1.25 (0.70 to 2.23$), 0, n=3$ & NA & NA & $\begin{array}{c}0.68(0.08 \text { to } 5.66) \\
N A, n=1\end{array}$ & 2.16 (0.58 to 8.08$), 0, n=2$ \\
\hline
\end{tabular}

$\mathrm{NA}=$ not applicable (only one study reporting on this risk factor-outcome comparison).

*Statistically significant.

†Children up to 18 years of age or as defined by original study. 


\begin{tabular}{|c|c|c|c|c|c|}
\hline Variables & Pneumonia & $\begin{array}{l}\text { All cause hospital } \\
\text { admission }\end{array}$ & $\begin{array}{l}\text { Intensive care unit } \\
\text { admission }\end{array}$ & Ventilator support & All cause mortality \\
\hline \multicolumn{6}{|l|}{ Sex and age: } \\
\hline Male sex & $\begin{array}{c}1.23(0.99 \text { to } 1.52), 0 \\
n=10\end{array}$ & $\begin{array}{c}0.99(0.93 \text { to } 1.05), 24 \\
n=12\end{array}$ & 0.93 (0.86 to 1.01$), 0, n=19$ & $\begin{array}{c}1.31(0.80 \text { to } 2.12), 0 \\
n=15\end{array}$ & 1.04 (0.94 to 1.16$), 5, \mathrm{n}=64$ \\
\hline Elderly $v$ non-elderly adults & $\begin{array}{c}1.67(0.36 \text { to } 7.77), 74 \\
n=3\end{array}$ & $\begin{array}{c}\left.2.84^{*} \text { (1.76 to } 4.59\right), 84 \\
n=7\end{array}$ & $0.62^{*}(0.39$ to 1.00$), 36, n=6$ & $\begin{array}{c}0.71(0.28 \text { to } 1.77), 0 \\
n=7\end{array}$ & $\begin{array}{c}2.69^{*}(1.53 \text { to } 4.71), 86 \\
n=29\end{array}$ \\
\hline $\begin{array}{l}\text { Paediatric } \dagger v \text { non-elderly } \\
\text { adults }\end{array}$ & $\begin{array}{c}0.34(0.10 \text { to } 1.15), 45 \\
n=3\end{array}$ & $\begin{array}{l}0.79^{*}(0.64 \text { to } 0.98), 72 \\
n=7\end{array}$ & 0.65 (0.33 to 1.26$), 73, n=7$ & $\begin{array}{c}0.68(0.35 \text { to } 1.31), 0 \\
n=7\end{array}$ & $\begin{array}{c}0.28^{*}(0.19 \text { to } 0.41), 39 \\
n=21\end{array}$ \\
\hline $2-<5$ years $v 5-<18$ years & $\begin{array}{c}2.05^{\star}(1.26 \text { to } 3.33), 0, \\
n=2\end{array}$ & $0.96(0.52$ to 1.75$), 0, n=2$ & $0.79^{*}$ (0.64 to 0.97$), 0, n=7$ & $\begin{array}{c}1.29(0.59 \text { to } 2.85), 0 \\
n=2\end{array}$ & $0.46(0.20$ to 1.07$), 38, n=7$ \\
\hline$<5$ years $\vee 5-<18$ years & $\begin{array}{c}1.56^{*}(1.07 \text { to } 2.26), 0 \\
n=3\end{array}$ & $\begin{array}{c}2.97^{*}(2.55 \text { to } 3.45), 24, \\
n=6\end{array}$ & $\begin{array}{c}0.66^{*}(0.53 \text { to } 0.84), 23 \\
n=12\end{array}$ & $\begin{array}{c}0.97(0.52 \text { to } 1.82), 0 \\
\mathrm{n}=6\end{array}$ & $\begin{array}{c}0.59 \text { (0.29 to } 1.22), 49 \\
n=15\end{array}$ \\
\hline$<2$ years $v 2-<18$ years & $\begin{array}{c}1.05(0.71 \text { to } 1.55), 0 \\
n=3\end{array}$ & $\begin{array}{c}5.38(0.45 \text { to } 64.52), N A \text {, } \\
n=1\end{array}$ & $0.53^{*}(0.37$ to 0.75$), 0, n=5$ & $\begin{array}{c}0.74(0.26 \text { to } 2.08), 25 \\
n=4\end{array}$ & $0.53(0.17$ to 1.64$), 0, n=6$ \\
\hline $\begin{array}{l}<6 \text { months } v 6 \text { months to } \\
<2 \text { years }\end{array}$ & $\begin{array}{c}1.03(0.20 \text { to } 5.37), 0 \\
n=2\end{array}$ & NA, NA & $1.83(0.47$ to 7.11$), 0, n=2$ & $\begin{array}{c}3.33(0.03 \text { to } 343.77), \\
69, n=2\end{array}$ & 1.00 (0.17 to 5.98$), N A, n=1$ \\
\hline \multicolumn{6}{|l|}{ Ethnicity: } \\
\hline Asian/Pacific $v$ white & NA & 1.60 (0.91 to 2.70$), 0, n=2$ & 1.12 (0.61 to 2.08$), 0, n=4$ & NA & $0.64(0.40$ to 1.03$), 0, n=5$ \\
\hline Black $v$ white & NA & $2.19^{*}(1.52$ to 3.16$), 0, n=3$ & $0.53^{*}(0.36$ to 0.78$), 0, n=5$ & NA & $0.70(0.42$ to 1.18$), 11, n=6$ \\
\hline Hispanic $v$ white & NA & $1.93^{*}(1.38$ to 2.70$), 0, n=3$ & $0.80(0.57$ to 1.14$), 0, n=4$ & NA & $0.76(0.48$ to 1.19$), 36, n=4$ \\
\hline Native American $v$ white & $\begin{array}{c}1.49 \text { (0.56 to } 3.92), N A \\
n=1\end{array}$ & $\begin{array}{c}3.07 \text { (0.62 to } 15.20), N A \\
n=1\end{array}$ & 0.95 (0.79 to 1.13$), 0, n=5$ & NA & $0.93(0.67$ to 1.30$), 0, n=4$ \\
\hline Native Australian $v$ white & NA & $\begin{array}{c}0.40^{*}(0.21 \text { to } 0.75), N A \\
n=1\end{array}$ & $0.91(0.73$ to 1.14$), 0, n=3$ & NA & $0.57(0.12$ to 2.69$), 47, n=3$ \\
\hline \multicolumn{6}{|l|}{$\begin{array}{l}\text { Pregnancy and postpartum } \\
\text { period: }\end{array}$} \\
\hline Pregnancy & $\begin{array}{c}1.13(0.76 \text { to } 1.67), 69 \\
n=7\end{array}$ & $\begin{array}{c}3.50^{*}(1.65 \text { to } 7.40), 90 \\
n=7\end{array}$ & $\begin{array}{c}0.62^{*}(0.52 \text { to } 0.75), 67 \\
n=19\end{array}$ & $\begin{array}{c}1.12(0.42 \text { to } 2.99), 58 \\
n=8\end{array}$ & $\begin{array}{c}0.99(0.67 \text { to } 1.46), 62 \\
n=26\end{array}$ \\
\hline$<4$ weeks post partum & $\begin{array}{c}3.62(0.42 \text { to } 30.9), N A \\
n=1\end{array}$ & NA & 2.34 (0.56 to 9.82$), N A, n=1$ & $\begin{array}{c}1.43(0.33 \text { to } 6.32), N A \text {, } \\
n=1\end{array}$ & $4.43^{*}(1.24$ to 15.81$), 0, n=3$ \\
\hline $\begin{array}{l}\text { 3rd trimester } v 1 \text { st or } 2 \text { nd } \\
\text { trimester }\end{array}$ & $\begin{array}{c}0.97(0.78 \text { to } 1.20), N A, \\
n=1\end{array}$ & $\begin{array}{c}3.98^{*}(1.65 \text { to } 9.57), 88 \\
n=2\end{array}$ & $1.48^{*}$ (1.05 to 2.09$), 0, n=3$ & NA & $1.22^{*}$ (1.01 to 1.48$), 0, n=5$ \\
\hline $\begin{array}{l}\text { Any risk factor or } \\
\text { comorbidity }\end{array}$ & $\begin{array}{c}1.19(0.64 \text { to } 2.22), 61 \\
n=10\end{array}$ & $\begin{array}{l}2.73^{*}(1.89 \text { to } 3.95), 95 \\
n=14\end{array}$ & $\begin{array}{c}1.93^{*}(1.59 \text { to } 2.35), 63 \\
n=27\end{array}$ & $\begin{array}{c}1.60(0.96 \text { to } 2.69), 12 \\
n=14\end{array}$ & $\begin{array}{c}2.77^{*}(1.90 \text { to } 4.05), 88, \\
n=53\end{array}$ \\
\hline \multicolumn{6}{|l|}{ Weight (body mass index): } \\
\hline Obese $(>30)$ & $\begin{array}{c}1.44(0.99 \text { to } 2.10), N A \text {, } \\
n=1\end{array}$ & $\begin{array}{c}3.44^{*}(2.14 \text { to } 5.54), 71 \\
n=8\end{array}$ & $\begin{array}{c}1.81^{*}(1.48 \text { to } 2.22), 48 \\
n=16\end{array}$ & $\begin{array}{c}1.79^{*}(1.38 \text { to } 2.32), 0 \\
n=9\end{array}$ & $\begin{array}{c}2.74^{*}\left(\begin{array}{c}1.56 \text { to } 4.80), 92, \\
n=33\end{array}\right.\end{array}$ \\
\hline Underweight $(<18.5)$ & $\begin{array}{c}1.06(0.41 \text { to } 2.76), N A, \\
n=1\end{array}$ & NA & $\begin{array}{c}1.26(0.52 \text { to } 3.04), n \text { NA, } \\
n=1\end{array}$ & $\begin{array}{c}0.56(0.16 \text { to } 1.98), N A \text {, } \\
n=1\end{array}$ & 1.35 (0.43 to 4.22$), N A, n=1$ \\
\hline \multicolumn{6}{|l|}{ Lung disease: } \\
\hline Any chronic lung disease & $\begin{array}{c}1.19(0.12 \text { to } 11.44), 0 \\
n=2\end{array}$ & $\begin{array}{c}2.37^{*}(1.56 \text { to } 3.61), 89, \\
n=9\end{array}$ & $1.48^{*}$ (1.19 to 1.83 ), $47, \mathrm{n}=2$ & $\begin{array}{c}1.06(0.35 \text { to } 3.15), 0 \\
n=5\end{array}$ & $\begin{array}{c}1.71^{*}(1.17 \text { to } 2.51), 79 \\
n=27\end{array}$ \\
\hline Asthma & $\begin{array}{c}1.88(0.87 \text { to } 4.08), 0 \\
n=4\end{array}$ & $1.40(0.96$ to 2.03$), 42, n=4$ & $0.83(0.59$ to 1.17$), 25, \mathrm{n}=18$ & $\begin{array}{c}0.91(0.36 \text { to } 2.31), 0 \\
n=9\end{array}$ & $\begin{array}{c}0.92(0.49 \text { to } 1.28), 31 \\
n=21\end{array}$ \\
\hline $\begin{array}{l}\text { Chronic obstructive } \\
\text { pulmonary disease }\end{array}$ & $\begin{array}{c}1.11(0.03 \text { to } 46.71) \\
79, n=2\end{array}$ & $\begin{array}{c}8.00(0.58 \text { to } 110.27), N A \text {, } \\
n=1\end{array}$ & $1.84^{*}(1.40$ to 2.41$), 50, n=5$ & 2.46 (0.62 to 9.74$), 37$ & $1.49^{*}(1.15$ to 1.92$), 0, n=13$ \\
\hline Obstructive sleep apnoea & NA & NA & $\begin{array}{c}1.70(0.06 \text { to } 47.95), N A \text {, } \\
n=1\end{array}$ & NA & $2.63^{*}$ ( 1.25 to 5.52$), 0, n=2$ \\
\hline \multicolumn{6}{|l|}{ Cardiovascular disease: } \\
\hline $\begin{array}{l}\text { Any cardiovascular } \\
\text { disease }\end{array}$ & $\begin{array}{c}0.92(0.44 \text { to } 1.93), 0 \\
n=3\end{array}$ & $\begin{array}{c}3.54^{*}(2.29 \text { to } 5.47), 71, \\
n=9\end{array}$ & $\begin{array}{l}1.70^{*}(1.39 \text { to } 2.08), 55 \\
n=17\end{array}$ & $\begin{array}{c}1.66(0.78 \text { to } 3.56), 0 \\
n=7\end{array}$ & $\begin{array}{c}2.92^{*}(1.76 \text { to } 4.86), 89, \\
n=28\end{array}$ \\
\hline Hypertension & NA & $\begin{array}{c}0.80(0.24 \text { to } 2.65), N A, \\
n=1\end{array}$ & 0.87 ( 0.49 to 1.58$), 0, n=4$ & $\begin{array}{c}0.82(0.19 \text { to } 3.50), 0 \\
n=3\end{array}$ & $1.49^{\star}$ ( 1.10 to 2.01$), 0, n=7$ \\
\hline Cerebrovascular insult & NA & $\begin{array}{c}5.83^{*}(1.52 \text { to } 22.27), N A \\
n=1\end{array}$ & NA & NA & 2.27 ( 0.77 to 6.71$), 0, n=2$ \\
\hline
\end{tabular}




\section{Table 4 (continued)}

\begin{tabular}{|c|c|c|c|c|c|}
\hline Variables & Pneumonia & $\begin{array}{l}\text { All cause hospital } \\
\text { admission }\end{array}$ & $\begin{array}{l}\text { Intensive care unit } \\
\text { admission }\end{array}$ & Ventilator support & All cause mortality \\
\hline Immunocompromised host & $\begin{array}{c}0.56(0.12 \text { to } 2.56), N A \\
n=1\end{array}$ & $\begin{array}{c}\left.4.61^{*} \text { (2.41 to } 8.82\right), 85 \\
n=11\end{array}$ & $1.02(0.78$ to 1.33$), 28, n=16$ & $\begin{array}{c}1.40(0.43 \text { to } 4.53), 0 \\
n=5\end{array}$ & $\begin{array}{c}3.67^{*}(1.78 \text { to } 7.58), 94, \\
n=23\end{array}$ \\
\hline HIV & $\begin{array}{c}1.78(0.90 \text { to } 3.53), 0 \\
n=2\end{array}$ & NA & 0.94 (0.28 to 3.22), NA, $n=1$ & $\begin{array}{c}0.80(0.25 \text { to } 2.58), 0 \\
n=4\end{array}$ & 0.97 (0.47 to 1.99$), 7, \mathrm{n}=9$ \\
\hline Chronic steroid therapy & NA & $\begin{array}{l}2.19(0.20 \text { to } 24.38), N A \text {, } \\
n=1\end{array}$ & 0.83 (0.28 to 2.48$), N A, n=2$ & NA & 1.54 (0.69 to 3.44$), N A, n=1$ \\
\hline Malignancy & $\begin{array}{c}0.75(0.28 \text { to } 2.00), N A, \\
n=1\end{array}$ & $\begin{array}{c}4.77^{*}(2.10 \text { to } 10.83), 0, \\
n=3\end{array}$ & 1.37 (0.99 to 1.90$), 50, n=9$ & $\begin{array}{c}1.46(0.47 \text { to } 4.51), 0 \\
n=5\end{array}$ & $3.10^{*}$ (2.35 to 4.10$), 0, n=12$ \\
\hline \multicolumn{6}{|l|}{ Neurological disease: } \\
\hline $\begin{array}{l}\text { Any neuromuscular } \\
\text { disease }\end{array}$ & $\begin{array}{c}1.00(0.53 \text { to } 1.90), 0 \\
n=3\end{array}$ & $\begin{array}{c}2.64^{*}\left(\begin{array}{c}1.57 \text { to } 4.43), 15 \\
n=6\end{array}\right.\end{array}$ & $2.63^{*}(1.83$ to 3.79$), 0, n=8$ & $\begin{array}{c}1.93(0.67 \text { to } 5.54), 26 \\
n=4\end{array}$ & $\begin{array}{c}2.68^{*}(1.91 \text { to } 3.75), 25 \\
n=16\end{array}$ \\
\hline Neurocognitive disease & NA & $\begin{array}{c}\left.14.69^{*} \text { (8.96 to } 24.08\right), 0 \\
n=2\end{array}$ & $2.26^{\star}(1.49$ to 3.45$), 0, n=4$ & $\begin{array}{c}5.90^{*}(1.21 \text { to } 28.77), \\
30, n=2\end{array}$ & $\begin{array}{c}5.01(0.48 \text { to } 52.34), 97, \\
n=8\end{array}$ \\
\hline Seizure & $\begin{array}{c}0.78(0.03 \text { to } 23.53) \\
N A, n=1\end{array}$ & $\begin{array}{c}\left.4.76^{*} \text { (1.61 to } 14.02\right), \mathrm{NA} \\
\mathrm{n}=1\end{array}$ & $1.51(0.59$ to 3.83$), 54, n=3$ & $\begin{array}{c}1.31(0.10 \text { to } 16.55), 14 \\
n=2\end{array}$ & 1.46 (0.93 to 2.31$), 0, n=7$ \\
\hline \multicolumn{6}{|l|}{ Other risk factors: } \\
\hline $\begin{array}{l}\text { Alcohol with or without } \\
\text { illicit drug use }\end{array}$ & $\begin{array}{c}0.57(0.15 \text { to } 2.12), N A \text {, } \\
n=1\end{array}$ & $\begin{array}{c}3.57(0.32 \text { to } 39.92), N A \\
n=1\end{array}$ & 1.70 (0.59 to 4.89$), N A, n=1$ & NA & $6.48(0.95$ to 44.16$), 0, n=2$ \\
\hline $\begin{array}{l}\text { Anaemia or } \\
\text { haemoglobinopathy }\end{array}$ & $\begin{array}{c}0.78(0.03 \text { to } 23.53) \\
N A, n=1\end{array}$ & $\begin{array}{l}6.55^{*}(2.32 \text { to } 18.52), 0, \\
n=3\end{array}$ & 1.28 (0.54 to 3.08$), 0, n=3$ & $\begin{array}{c}0.28(0.03 \text { to } 2.82), 0 \\
n=2\end{array}$ & $2.28^{*}(1.35$ to 3.84$), 0, n=8$ \\
\hline Autoimmune disease & NA & 3.73 ( 0.82 to 17.06$), 0, n=2$ & $\begin{array}{c}29.05^{\star}(1.49 \text { to } 567.79), N A \text {, } \\
n=1\end{array}$ & $\begin{array}{c}0.81(0.03 \text { to } 22.24) \\
\text { NA, } n=1\end{array}$ & 4.96 (0.41 to 60.6$), 58, n=3$ \\
\hline Diabetes mellitus & $\begin{array}{c}0.97(0.30 \text { to } 3.12), 0 \\
n=2\end{array}$ & $\begin{array}{l}4.26^{*}(3.14 \text { to } 5.77), 31 \\
n=9\end{array}$ & $\begin{array}{c}1.60^{*}(1.32 \text { to } 1.94), 37 \\
n=18\end{array}$ & $\begin{array}{c}1.54(0.60 \text { to } 3.91), 0 \\
n=8\end{array}$ & $\begin{array}{c}2.21^{*}(1.37 \text { to } 3.57), 86, \\
n=32\end{array}$ \\
\hline Endocrinological disease & NA & $\begin{array}{l}4.00^{*}(2.23 \text { to } 7.18), N A, \\
n=1\end{array}$ & $\begin{array}{c}1.49(0.18 \text { to } 12.45), N A, \\
n=1\end{array}$ & NA & NA \\
\hline Gastrointestinal disease & NA & $\begin{array}{c}1.47(0.15 \text { to } 14.36), N A \\
n=1\end{array}$ & 0.47 (0.06 to 3.93 ), NA, $n=1$ & NA & 0.97 ( 0.60 to 1.59$), 23, n=2$ \\
\hline Liver disease & NA & 1.93 (0.29 to 12.72$), 0, n=2$ & $2.65^{\star}$ ( 1.44 to 4.88$), 0, n=6$ & $\begin{array}{c}8.11(0.17 \text { to } 377.11) \\
66, n=2\end{array}$ & $2.00^{*}(1.32$ to 3.04$), 22, n=8$ \\
\hline Metabolic disease & $\begin{array}{c}0.66(0.17 \text { to } 2.53), N A, \\
n=1\end{array}$ & $0.62(0.17$ to 2.24$), 0, n=2$ & 2.77 (0.36 to 21.33$), 65, n=2$ & $\begin{array}{c}14.22^{*}(3.35 \text { to } 60.34) \\
\text { NA, } n=1\end{array}$ & $1.83^{*}$ ( 1.19 to 2.79$), 54, \mathrm{n}=4$ \\
\hline $\begin{array}{l}\text { Prematurity or preterm } \\
\text { birth }\end{array}$ & $\begin{array}{c}2.33(0.28 \text { to } 19.22), 0, \\
n=2\end{array}$ & $\begin{array}{c}31.59^{*}(1.80 \text { to } 552.94) \\
\text { NA, } n=1\end{array}$ & 1.25 (0.47 to 3.31$), 87, \mathrm{n}=2$ & $\begin{array}{c}10.41^{*}(1.02 \text { to } 106.13) \\
0, n=2\end{array}$ & $1.94(0.76$ to 4.98$), 0, n=4$ \\
\hline Renal disease & $\begin{array}{c}0.20 \text { (0.01 to } 5.57), N A, \\
n=1\end{array}$ & $\begin{array}{c}\left.5.11^{*} \text { (2.50 to } 10.42\right), 46 \\
n=5\end{array}$ & $\begin{array}{c}1.27(0.88 \text { to } 1.84), N A, \\
n=11\end{array}$ & $\begin{array}{c}1.65(0.07 \text { to } 36.96), 70 \\
n=3\end{array}$ & $\begin{array}{c}3.11^{*}(1.54 \text { to } 6.28), 90, \\
n=16\end{array}$ \\
\hline $\begin{array}{l}\text { NA=not applicable (only on } \\
{ }^{*} \text { Statistically significant. } \\
\text { †Children up to } 18 \text { years of }\end{array}$ & e study reporting on this & risk factor-outcome compar & rison). & & \\
\hline
\end{tabular}


Table 5| Risk estimates of identified risk factors during pandemic ( $p$ ) and seasonal (s) influenza, and assessment of quality of evidence using an adaptation of the GRADE approach

\begin{tabular}{|c|c|c|c|c|c|c|c|c|c|c|c|c|c|c|c|}
\hline \multirow[b]{2}{*}{ Risk factors } & \multicolumn{2}{|c|}{ Pneumonia } & \multicolumn{2}{|c|}{$\begin{array}{c}\text { All cause } \\
\text { hospital } \\
\text { admission }\end{array}$} & \multicolumn{2}{|c|}{$\begin{array}{r}\text { Intensive } \\
\text { care unit } \\
\text { admission }\end{array}$} & \multicolumn{2}{|c|}{$\begin{array}{c}\text { Ventilator } \\
\text { support } \\
\end{array}$} & \multicolumn{2}{|c|}{$\begin{array}{l}\text { All cause } \\
\text { mortality } \\
\end{array}$} & \multirow{2}{*}{$\begin{array}{l}\text { Study } \\
\text { design }\end{array}$} & \multirow[b]{2}{*}{ Inconsistency } & \multirow[b]{2}{*}{ Imprecision } & \multirow{2}{*}{$\begin{array}{c}\text { Strong } \\
\text { evidence of } \\
\text { association }\end{array}$} & \multirow[b]{2}{*}{ GRADE } \\
\hline & $\mathbf{P}$ & $\mathbf{S}$ & $\mathbf{P}$ & S & $\mathbf{P}$ & $\mathbf{S}$ & $\mathbf{P}$ & $\mathbf{S}$ & $\mathbf{P}$ & $\mathbf{S}$ & & & & & \\
\hline \multicolumn{16}{|l|}{ Sex and age: } \\
\hline $\begin{array}{l}\text { Elderly } v \text { non-elderly } \\
\text { adults }\end{array}$ & * & Ntrl & + & + & $(+)$ & NA & Ntrl & NA & + & + & Down & Down & & Up & Very low \\
\hline $\begin{array}{l}\text { Paediatric } v \\
\text { non-elderly adults }\end{array}$ & $\left({ }^{\star}\right)$ & $\left({ }^{*}\right)$ & $(+)$ & NA & $\left({ }^{\star}\right)$ & NA & Ntrl & NA & $\left({ }^{*}\right)$ & Ntrl & Down & Down & & & Very low \\
\hline \multicolumn{16}{|l|}{$\begin{array}{l}\text { Pregnancy and } \\
\text { postpartum period: }\end{array}$} \\
\hline$<4$ weeks post partum & * & NA & NA & NA & * & NA & Ntrl & NA & + & NA & Down & & Down & Up & Very low \\
\hline $\begin{array}{l}\text { 3rd trimester } v 1 \mathrm{st} / 2 \mathrm{nd} \\
\text { trimester }\end{array}$ & Ntrl & NA & + & NA & + & NA & NA & NA & + & NA & Down & & & & Very low \\
\hline $\begin{array}{l}\text { Prematurity or preterm } \\
\text { birth }\end{array}$ & * & NA & + & NA & Ntrl & NA & + & NA & * & NA & Down & & Down & Up & Very low \\
\hline $\begin{array}{l}\text { Any risk factor or } \\
\text { comorbidity }\end{array}$ & Ntrl & + & + & + & + & + & * & * & + & + & Down & & & Up & Low \\
\hline Obesity $(\mathrm{BMI}>30)$ & Ntrl & NA & + & NA & + & NA & + & NA & + & + & Down & & & Up & Low \\
\hline \multicolumn{16}{|l|}{ Lung disease: } \\
\hline $\begin{array}{l}\text { Any chronic lung } \\
\text { disease }\end{array}$ & Ntrl & * & + & + & + & + & Ntrl & + & + & * & Down & & & & Very low \\
\hline Asthma & * & + & Ntrl & NA & Ntrl & Ntrl & Ntrl & NA & Ntrl & Ntrl & Down & & & & Very low \\
\hline $\begin{array}{l}\text { Chronic obstructive } \\
\text { pulmonary disease }\end{array}$ & Ntrl & NA & * & NA & + & NA & * & + & + & Ntrl & Down & & Down & & Very low \\
\hline $\begin{array}{l}\text { Obstructive sleep } \\
\text { apnoea }\end{array}$ & NA & NA & NA & NA & * & NA & NA & NA & + & NA & Down & & Down & & Very low \\
\hline \multicolumn{16}{|l|}{$\begin{array}{l}\text { Cardiovascular } \\
\text { disease: }\end{array}$} \\
\hline $\begin{array}{l}\text { Any cardiovascular } \\
\text { disease }\end{array}$ & Ntrl & + & + & + & + & Ntrl & * & + & + & + & Down & & & Up & Low \\
\hline Hypertension & NA & NA & Ntrl & NA & Ntrl & NA & Ntrl & NA & + & * & Down & & Down & & Very low \\
\hline Cerebrovascular insult & NA & NA & + & NA & NA & NA & NA & NA & * & Ntrl & Down & & Down & & Very low \\
\hline \multicolumn{16}{|l|}{ Immunosuppression: } \\
\hline $\begin{array}{l}\text { Immunocompromised } \\
\text { participant }\end{array}$ & $\left(^{*}\right)$ & $(+)$ & + & NA & Ntrl & $\left({ }^{\star}\right)$ & Ntrl & NA & + & + & Down & Down & Down & Up & Very low \\
\hline HIV & * & NA & NA & NA & Ntrl & NA & Ntrl & NA & Ntrl & * & Down & & & & Very low \\
\hline $\begin{array}{l}\text { Chronic steroid } \\
\text { therapy }\end{array}$ & NA & NA & * & + & Ntrl & NA & $(+)$ & NA & * & * & Down & & Down & & Very low \\
\hline Malignancy & Ntrl & Ntrl & + & + & Ntrl & NA & Ntrl & NA & + & * & Down & & Down & Up & Very low \\
\hline \multicolumn{16}{|l|}{ Neurological disease: } \\
\hline $\begin{array}{l}\text { Any neuromuscular } \\
\text { disease }\end{array}$ & Ntrl & * & + & NA & + & NA & * & NA & + & + & Down & & & Up & low \\
\hline $\begin{array}{l}\text { Neurocognitive } \\
\text { disease }\end{array}$ & NA & + & + & NA & + & * & + & NA & + & Ntrl & Down & & Down & Up & Very low \\
\hline Seizure & Ntrl & Ntrl & + & NA & * & NA & Ntrl & NA & Ntrl & * & Down & & Down & & Very low \\
\hline \multicolumn{16}{|l|}{ Other risk factors: } \\
\hline $\begin{array}{l}\text { Anaemia or } \\
\text { haemoglobinopathy }\end{array}$ & Ntrl & $\left({ }^{\star}\right)$ & + & NA & Ntrl & $\left({ }^{*}\right)$ & $\left({ }^{*}\right)$ & NA & + & NA & Down & & & & Very low \\
\hline Autoimmune disease & NA & NA & * & NA & + & NA & Ntrl & NA & * & NA & Down & & Down & & Very low \\
\hline Diabetes mellitus & Ntrl & Ntrl & + & + & + & NA & * & NA & + & $\left({ }^{*}\right)$ & Down & Down & & & Very low \\
\hline $\begin{array}{l}\text { Endocrinological } \\
\text { disease }\end{array}$ & NA & NA & + & NA & Ntrl & NA & NA & NA & NA & + & Down & & Down & & Very low \\
\hline Liver disease & NA & NA & * & NA & + & NA & * & NA & + & $\left({ }^{*}\right)$ & Down & & Down & & Very low \\
\hline Metabolic disease & $\left({ }^{*}\right)$ & Ntrl & $\left({ }^{*}\right)$ & NA & * & NA & + & NA & + & $\left({ }^{*}\right)$ & Down & Down & & & Very low \\
\hline
\end{tabular}


Table 5 (continued)

\begin{tabular}{|c|c|c|c|c|c|c|c|c|c|c|c|c|c|c|c|}
\hline \multirow[b]{2}{*}{ Risk factors } & \multicolumn{2}{|c|}{ Pneumonia } & \multicolumn{2}{|c|}{$\begin{array}{c}\text { All cause } \\
\text { hospital } \\
\text { admission }\end{array}$} & \multicolumn{2}{|c|}{$\begin{array}{c}\text { Intensive } \\
\text { care unit } \\
\text { admission }\end{array}$} & \multicolumn{2}{|c|}{$\begin{array}{c}\text { Ventilator } \\
\text { support }\end{array}$} & \multicolumn{2}{|c|}{$\begin{array}{l}\text { All cause } \\
\text { mortality }\end{array}$} & \multirow{2}{*}{$\begin{array}{l}\text { Study } \\
\text { design }\end{array}$} & \multirow[b]{2}{*}{ Inconsistency } & \multirow[b]{2}{*}{ Imprecision } & \multirow{2}{*}{$\begin{array}{c}\text { Strong } \\
\text { evidence of } \\
\text { association }\end{array}$} & \multirow[b]{2}{*}{ GRADE } \\
\hline & $\mathbf{P}$ & S & $\mathbf{P}$ & S & $\mathbf{P}$ & S & $\mathbf{P}$ & S & $\mathbf{P}$ & $\mathrm{S}$ & & & & & \\
\hline Renal diseases & $\left({ }^{*}\right)$ & Ntrl & + & NA & Ntrl & NA & * & Ntrl & + & * & Down & Down & & Up & Very low \\
\hline
\end{tabular}

GRADE=grading of recommendations assessment, development, and evaluation; COPD=chronic obstructive pulmonary disease; +=significant risk factor; *potential risk factor: odds ratio $>1.5$, trend; Ntrl=neutral; $\left({ }^{*}\right)=$ potentially protective: odds ratio $<0.67$, trend, $(+)=$ significant protective factor; $N A=$ not available. 


\section{Figure}

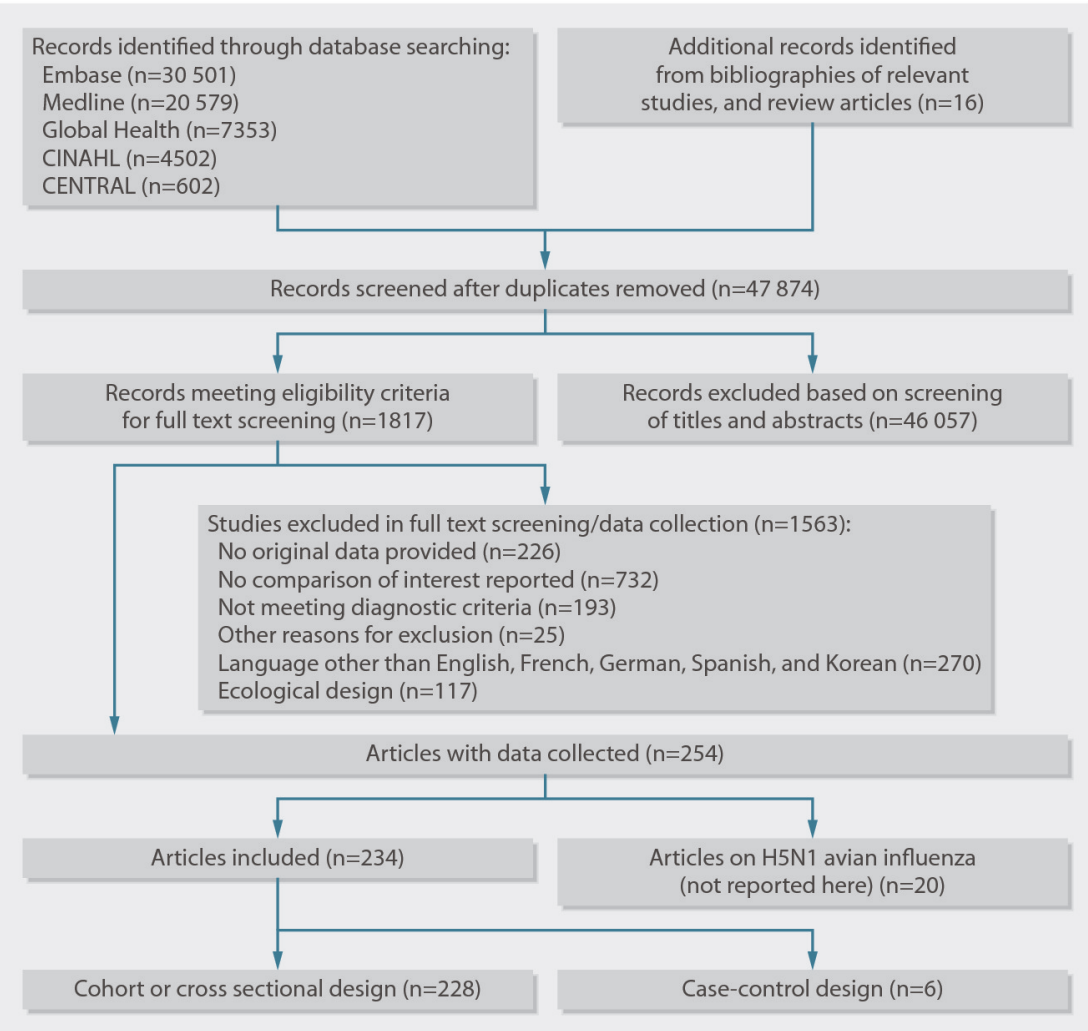

Flow of studies included and excluded 